Portland State University

PDXScholar

5-1-1969

\title{
Judging development and sexual identity in children's art
}

\author{
Susan Lathrop Dietsche \\ Portland State University \\ Helen Lieberman Fenske \\ Robert A. Jones \\ Robert D. Loy \\ Robert L. Smith
}

Follow this and additional works at: https://pdxscholar.library.pdx.edu/open_access_etds Let us know how access to this document benefits you.

\section{Recommended Citation}

Dietsche, Susan Lathrop; Fenske, Helen Lieberman; Jones, Robert A.; Loy, Robert D.; and Smith, Robert L., "Judging development and sexual identity in children's art" (1969). Dissertations and Theses. Paper 67. https://doi.org/10.15760/etd.67

This Thesis is brought to you for free and open access. It has been accepted for inclusion in Dissertations and Theses by an authorized administrator of PDXScholar. Please contact us if we can make this document more accessible: pdxscholar@pdx.edu. 
AN ABSTRACT OF THE GROUP PROJECT OF Susan Lathrop

Dietsche, Helen Lieberman Fenske, Robert A. Jones, Robert. D.

Loy, and Robert L. Smith for the Master of Social Work presented May 5, 1969.

Title: Judging Development and Sexual Identity in Children's Art.

APPROVED BY MEMBERS OF THE GROUP PROJECT COMMITTEE:

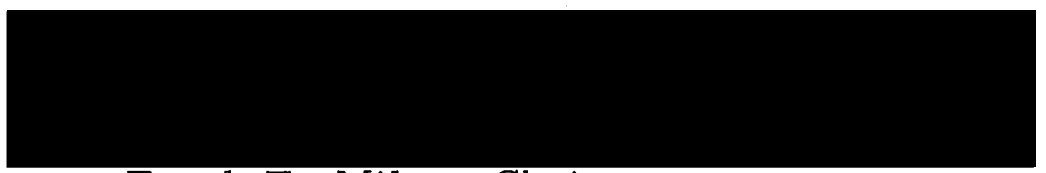

Frank F. Miles, Chairman

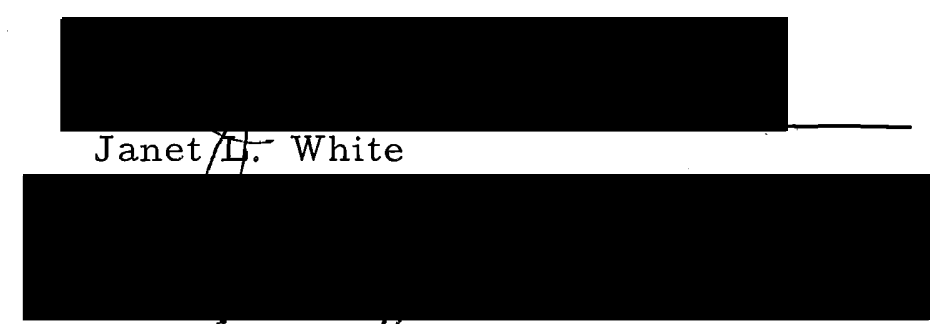

Byrớ J. Gardiner

This study identified selected characteristics of sexual identity and artistic development using 481 pictures from a collection of 1, 008 pictures drawn by first through fourth grade males and females. The pictures were collected by the E. C. Brown Trust Foundation to study children's concepts of reproduction.

Three general hypotheses were developed: I. Sex differences are observable in children's art; II. There are observable 
differences in artistic development as grade level changes; III. Observations by social workers of content in children's art are reliable. From a search of the literature, certain variables were identified, including content, use of color, and aspects of form, space, and execution. Hypotheses stating that these vary in relation to grade level and sex were developed to be tested.

Data were collected by means of a pretested schedule. A sample of sixty pictures was viewed by each of five observers, independently and blind. Data were transcribed and evaluated using tests of reliability and association.

The findings indicated that differences related to sex and grade level of the artist can be observed with statistical reliability by social workers. Three factors affected the interpretation of the findings: a number of uncontrolled variables; the absence of norms of children's art verified by research against which to measure findings; and the relatively low reliability of judgment.

Implications for social work are mainly cautionary. Art is such a complex and subjective matter that until parameters have been established by research, its use as a tool for evaluating human behavior cannot be recommended. 
JUDGING DEVELOPMENT AND SEXUAL IDENTITY IN CHILDREN'S ART

by

SUSAN LATHROP DIETSCHE

HELEN LIEBERMAN FENSKE

ROBERT A. JONES

ROBERT D. LOY

ROBERT L. SMITH

A group project submitted in partial fulfillment of the requirements for the degree of

MASTER OF SOCIAL WORK

Portland State University

1969 
TO THE OFFICE OF GRADUATE STUDIES:

The members of the Committee approve the group project of Susan Lathrop Dietsche, Helen Lieberman Fenske, Robert A. Jones, Robert D. Loy, and Robert L. Smith presented May 5, 1969.

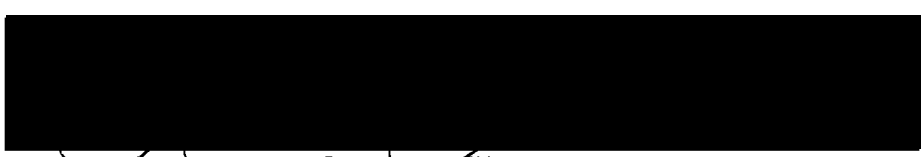

Frank F. Miles, Chairman

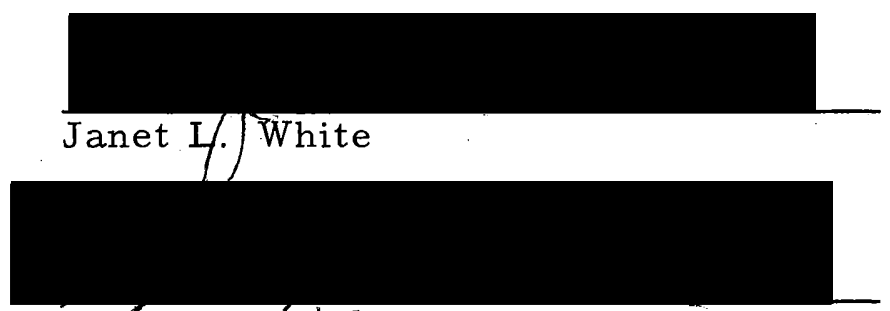

Byfon J. Gardner

APPROVED:

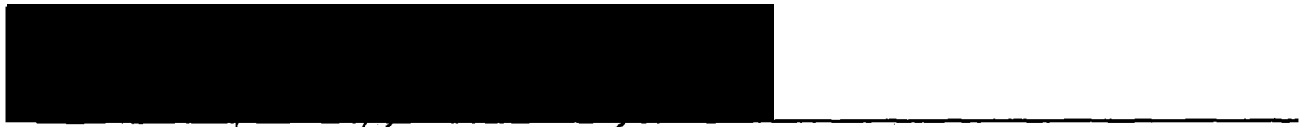

Daniel E. Jennihgs, Acting Dean, School of Social Work

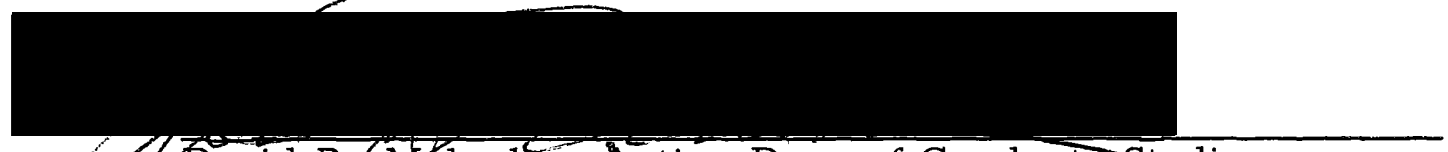

David R Malcolm, Acting Dean of Graduate Studies

May 7, 1969 


\section{TABLE OF CONTENTS}

PAGE

ACKNOW LEDGMENTS ........................ iii

LIST OF TABLES ........................... vi

\section{CHAPTER}

I INTRODUCTION ................. 1

Underlying Concepts ............ 2

Background of the Study.......... . 3

Review of the Literature ........ 6

II METHODOLOGY .............. 16

Population and Sample.......... 16

Schedule and Hypotheses ......... 18

Pretests...................... 30

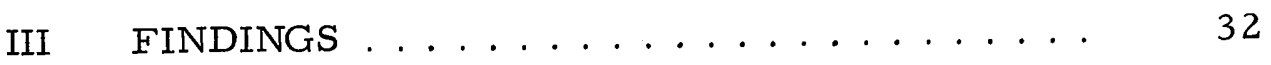

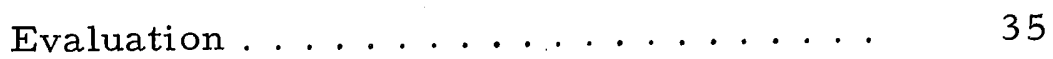

Conclusions .................. 48

Interpretation of Findings......... 49

Implications for Social Work. . . . . . 51 
PAGE

BIBLIOGRAPHY CITED . . . . . . . . . . . . . 54

GENERAL BIBLIOGRAPHY ............... 56

APPENDICES

A. REPRESENTATIVE PICTURES . . . . . . . 57

B. THE SCHEDULE ................... 59 


\section{LIST OF TABLES}

TABLE

PAGE

I Percentage of Agreement by Observers on

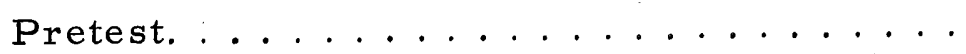

II Comparison of Percentages of Agreement and

z Scores for Pretest and Final Test .....

III Mean Number of People Depicted in Sample ....

IV Values of Comparisons Between Grade and

Sex of the Number of People Portrayed . . .

$\mathrm{V}$ Incidence of Elaboration ............

VI Mean Number of Colors Used by Grade and Sex. .

VII T Scores for the Differences in the Mean

Number of Colors Used by Grade and Sex...

VIII Number of Persons Using Selected Concepts

of Reproduction by Grade .......... 


\section{ACKNOW LEDGMENTS}

We wish to acknowledge with gratitude the assistance and materials provided to the group by the staff and administration of the E. C. Brown Trust Foundation. 


\section{CHAPTER I}

\section{INT RODUCTION}

This study proposes to identify and differentiate some characteristics of sexual identity and artistic development in children by utilizing 481 pictures taken from a collection of 1, 008 pictures drawn by first through fourth grade males and females. These pictures were a stratified sample collected by the E. C. Brown Trust Foundation for a proposed study of children's concepts of reproduction as projected through drawing.

One of the challenges in social work is to use data already collected for other purposes. While there are definite limitations as well as advantages in using others' data, this situation occurs frequently in social work. To explore how such data can be used, the group chose to investigate the use of children's art as a diagnostic tool.

The purpose of this study is to identify sex related and grade level related factors in children's art. While the group had some interest in attempting to determine the ability of social workers to make reliable judgments of the sex and grade of the individual artist, the main thrust was to identify factors of sexual identity and development in the entire sample. 


\section{UNDERLYING CONCEPTS}

The use of art as a formal tool for understanding developmental patterns in children is not widespread in social work. However, the art of children has become one of the common projective techniques employed by psychology and psychiatry for evaluating personality and intelligence. As social workers the group was not necessarily confined to these areas of interest. The use of projecttive material of children and the judgments made about growth and development by social workers seemed to be of interest to the field if these judgments were reliable.

From the point of view of the social worker we pose the following question: Are there differences, developmental and sexual, which can be judged reliably by a group of social workers? Many of the tools for evaluating people are subjective and intuitive, and dependent upon the experience of the social worker. It is especially important that tests such as those developed in this study be applied in an effort to identify what is subjective and what can be objectively measured. The interpretation of children's art is, in fact, being used diagnostically, and some measures need to be applied to determine reliability and validity.

A further reason for concern with children's art is that language is perhaps not the most useful tool for evaluating children. 
Play techniques have long been used in social work for helping a child to express his feelings and perceptions of his world. Art is another technique which, because of its permanence, can be subjected to more thorough investigation on many different levels by different observers.

The idea that children's art is sequentially developmental has been explored and hypothesized. The idea of sequential psychosexual development has also been explored and hypothesized. In an effort to see if these two strands of development were interrelated the two general hypotheses of this study were formulated:

I. Sex differences are observable in children's art.

II. There are observable differences in artistic development as grade level changes.

In order to work out a method of investigation so that the general hypotheses could be tested, a corrollary hypothesis emerged:

III. Observations by social workers of content in children's art are reliable.

\section{BACKGROUND OF THE STUDY}

The E. C. Brown Trust Foundation is a non-profit organization established in Portland, Oregon, in 1939 from the bulk of Dr. Ellis C. Brown's estate. This trust evolved from the Oregon Social Hygiene Society and has focused on sex education. 
In 1966 the E. C. Brown Trust Foundation undertook a project aimed at identifying concepts of human reproduction held by grade school children who had had no formal sex education through the school. For this purpose pictures drawn by first through fourth grade males and females were collected. Included in this group were a few pictures drawn by children in ungraded classrooms for the mentally retarded. The pictures were gathered from several schools in the Los Angeles, California, area and from several small Oregon towns. The pictures were motivated by one or more of the following questions:

1. What did you look like before you were born?

2. What does a baby look like before he is born?

3. Where were you before you were born?

4. Where is a baby before he is born?

There were no restrictions placed on the teachers regarding the media used for drawing. The majority of the pictures were drawn with crayon or poster paint; however, collage, finger paint, and pencil drawings were also produced. It is not known what materials were available to the children. The pictures were numbered by the E. C. Brown Trust Foundation and, with the exception of the fourth grade drawings, were photographed on transparencies. Illustrative reproductions of these may be seen in Appendix A.

When the E. C. Brown Trust Foundation staff was unable to 
arrive at a research design which suited its purposes, the Foundation advertised for other groups to use the drawings. Through this channel the idea for this study emerged.

The original research design of this study was developedaround the E. C. Brown Trust Foundation approach of identifying and quantifying concepts of reproduction in the drawings. This design had to be abandoned because the areas of quantifying and identifying content of children's art had not been explored extensively through research in any discipline. The result was that certain general aspects of the art of children were selected as areas of focus. Reproductive concepts shown in the drawings were considered in terms of pictorial content in the same manner as were the numbers of people, animals, and colors.

Based on a survey of the literature the group identified certain sets of developmental variables that seemed to warrant study. These variables included content of the picture, such as number and sex of people, animals, and objects. Other variables considered use of color, and certain aspects of form, space, and execution. The hypotheses state that these vary in relation to the grade level and sex of the artist. Specific hypotheses to test these variables were developed as statements relating to the concepts of Erikson, Gaitskell, Lowenfeld, and others. These sources are discussed in the following section; the hypotheses are presented in the 
methodology section in conjunction with the schedule.

\section{REVIEW OF THE LITERATURE}

In the early phases of developing this study the members of the group searched for theory and empirical studies in areas including the use of projective techniques in psychology, the psychoanalytic study of the child, creative development, art therapy, and art education. Because data on the children who produced the E. C. Brown Trust Foundation drawings were limited to grade and sex, verified conclusions about the child's internal psychological processes or individual development could not be made. Bibliographical references are, for this reason, limited to material relevant to the major hypotheses.

The literature was explored especially for studies concerning the developmental nature of children's art and for those concerning the sexual development of children as expressed through their art. These matters led to a review of literature primarily in the fields of art education and in projective psychology. Much of the literature contained hypotheses which were not supported by research. Therefore, several of the areas investigated by this study were motivated by the lack of previous investigation or by conflicting theories. The following review is not a full chronological or topical report on the literature covered but, rather, is limited to that most pertinent to 
this study.

Testing Erikson's (1) observations about the sex differences in children's play configurations was one phase of this study. Erikson noted that there were construction patterns which expressed a sense of being male or female. His conclusions resulted from an intimate knowledge of the child's background, history, and physical appearance rather than from formal research. His observations led this group to question whether these patterns could be distinguished with only the configuration (or picture) available. It was also necessary to translate his design which applied to three dimensional play materials into a design which applied to drawings.

The specific configurations Erikson identified that are applicable to art include:

1. Towers or tall structures are masculine.

2. Motorcars and machines are masculine.

3. Girls use more people inside houses than boys use.

4. Openness, or lack of interior walls, and open doors are feminine characteristics.

5. Boys focus on outward or upward movement.

6. Boys show channelization.

7. Girls focus on the interiors of homes. (1, pp. 97-108)

Gaitskell (2) concerned himself with the philosophy of art education and the artistic development of children. He sees the 
objectives of art education as encompassing the following tenets: a belief in the creative ability of all children; a belief in the integrated acquisition of skills; a belief in the necessity for freedom of thought; a belief in experience as the basis for expression; emphasis upon the development of taste; and a belief that art can help develop worthy citizens by making order out of disorder, calling for self-discipline, and assisting one in relating to the environment.

Art educators are most often concerned with evaluation of the elements of form or design in art. These elements are line, mass and space, light and shade, texture and color. A good design consists of a satisfactory arrangement of the elements in a coherent, organized, and complete manner. Unity of design is created by rhythms, balance, and centers of interest.

Expression in art relies upon both the unique personal qualities of its creator and the experiences he has had in his life. Nevertheless, during certain periods of their development all children tend to pass through several stages of artistic production and consequently adopt recognizable modes of artistic expression. Before kindergarten and first grade most children are in the stage of manipulation, or scribble stage. In this stage the child manipulates his materials in a random and exploratory manner. This becomes increasingly organized until shapes can be recognized and the child then begins to title his scribbles or designs because they remind him 
of objects.

Gaitskell notes that the stage of symbols is generally attained during the first three grades. In this stage the child has the ability to produce marks at will. He can create a precise statement of fact or event from his experience. The first symbols that appear seem to be those that have most forcibly impressed him in his experience. He may draw flowers, animals, furniture, or people, but most frequently human figures are represented. As skill improves these figures become differentiated symbols, and men, women, and children are shown. Once the ability to produce a symbol is established, the child relates the symbol to the environment. This occurs around age seven. At this stage sex differences are observable. Boys produce more symbols for mechanical objects than girls do. Boys depict animals more often than do girls, while girls draw a larger number of human beings.

In the early symbolic stage Gaitskell considers paper the environment for symbols. To emphasize this idea and to define the limits of the environment, children often put a border around the picture. The border precedes the use of a baseline which serves to relate the symbol to the environment. Following the use of baseline comes the skyline and the sun. The sky does not touch the earth until the child is eight to ten years old and has greater maturity of expression. This use of filled in background is a developmental 
characteristic and third graders do more of this than younger grade groups.

As symbols expand and grow in complexity, it is increasingly difficult for the child to find adequate modes of expression to make his meanings clear. In the symbolic stage Gaitskell observes that the child often draws the most important symbol the largest. Mother is larger than the house. The child is often the largest person in the picture. Favorite colors are used for important symbols with color being chosen for emotional appeal rather than for resemblance to the natural world. Realistic use of color does not usually occur until after age seven.

As the child moves into the pre-adolescent stage, grades three through six, his art is more cautious, more studied, and more complete. His central objects depict increasing reality so that details of facial features and clothing appear. Color tends to approximate reality, and depth is added.

Kellogg (3) has extensively researched the manipulation or scribble stage of children's art. She identifies twenty basic scribble patterns which are universal in children's art. She notes, "The bulk of the scribbling done by young children seems to give either a circular over-all effect, or one of crossing lines." (4, p. 68) Although most of Kellogg's concepts are stated in such a way that they could not be operationalized for this study, her observations 
are useful for investigating ideas about the child's artistic development in conjunction with his physical and emotional development.

Hausman (5), in his study of children's art work and their sociometric status, investigated a group of children as they interacted in the choice and rejection of friends and as they utilized art materials. The problem presented was the study of relationships between elements in children's art work and children's social status as measured by sociometric testing. It was found that the overchosen group of children utilized significantly greater amounts and larger sizes of paper, did more drawings, utilized a greater total amount of color, and utilized a greater amount and variety of media than did the other sociometric groups. In terms of these comparisons, the average chosen group can be ranked next to the overchosen group followed by the underchosen group. These findings suggest that there is a direct relationship between social status and the overt physical energies being expended by the child in using art materials. Of interest to this study are Hausman's findings regarding color. He found the overchosen children tended to use greater amounts of color as evidenced by the comparison of the total amounts of color and the major or dominant colors used. The average group ranked next and the underchosen group ranked last. There was no significant difference in the use of individual color and social status of the child using that color. 
Burns (6) made a study of correlations of design with personality. The study dealt with observed differences and statistical comparisons. Burns found that certain bold design groups such as diagonal structure, straight lines, and dark tonality had high scores in the ACF clusters (agressive, conventional, and power and toughness). By contrast, low scores in $\mathrm{ACF}$ clusters correlated with few straight lines, few diagonals, light tonality, and avoidance of black.

Although the study tested college women, the findings might be generalized to young children, and the $\mathrm{ACF}$ scores might correlate with masculine and feminine identification supporting the Eriksonian concepts of the upward motion and verticalness of males and circular modality of females.

Freyberger (7) studied differences in the creative drawings of children of varying ethnic and socio-economic backgrounds in Pennsylvania based on samplings of grades one through six. She found more similarities than differences in all the drawings and the differences that were found related to grade level rather than to ethnic or socio-economic background. The following are some of the similarities found:

Use of pure colors was much preferred to use of mixed colors. Preference was for more than five colors rather than for less than five colors. The preferred color was red. Second choice in color was blue. 
Primary colors were used twice as often as any of the other colors or groups of colors.

Baseline representations were used more than any other type of spatial awareness.

The number of human figures used most often was one. Drawings with figures were preferred to those without figures. A desire was expressed for decoration on objects, figures, and landscapes. However, decoration was more often found on objects than on figures or landscapes. (7, p. 123)

The following are some of the differences found by Freyberger:

First graders showed the least desire to use decoration. Third graders used the least decoration on objects. First graders had the fewest representations with meaningful environments.

First graders showed most preference for no relationship between color and the object. (7, p. 124)

Lowenfeld (8) has written in the field of art education. Many of his observations about development are illustrated by studies, and he has paid much attention to the developmental nature of certain artistic characteristics. Of particular interest to this study is his concept of the baseline as a symbolic representation that the child is ready for cooperative endeavors. The relationship of objects to a baseline is a correlate of the child's readiness to relate letters to one another and thus to read. Lowenfeld observes that seven to nine years is the usual age for the baseline to appear in the drawings of both boys and girls. (8, p. 109)

Lowenfeld (8), Gaitskell (2), and Horovitz (9) discuss the use of $\mathrm{x}-\mathrm{ray}$ in children's drawings. Lowenfeld indicates that the child uses $\mathrm{x}$-ray to show that part of his picture which is most important to 
him. (8, pp. 127-130) This differs from the use of $x-r a y$ as a technique for constructing the human body as described by Gaitskell. (2, p. 135) Gaitskell maintains that this is a building technique so that the child can clothe the figures; the $\mathrm{x}$-ray lines that remain are not intended to represent the most important part of the figure. Horovitz contends that $\mathrm{x}$-ray, or transparency, occurs most frequently from ages five through nine years and that girls show greater use of this technique than boys. (9, p. 57)

Horovitz remarks that a higher percentage of girls than boys, aged four through nine years, produce humans and houses. This is further elaborated to state that boys draw fewer female figures than do girls. Conversely, girls draw fewer male figures than do boys. (9, p. 31) Horovitz also noted that the younger the child, the greater the number of colors used. (9, pp. 192-193)

Corcoran (10), in his study of children's responses to color stimuli, asserted that there was an abundance of theories regarding the use of color, but relatively little evidence concerning the effects of color upon children. His investigation tested the hypothesis that the responses made by children to depth-size qualities of color, emotional qualities of color, and preferences for a particular color are the result of a random distribution of choices.

However, his study indicated that certain emotional qualities are felt to correspond with some of the colors presented. Yellow, 
red, and blue were perceived as "happy" colors. Purple and blue were seen to be "sad." "Excited" colors were purple and orange. Blue and yellow were regarded as "calm." All children in this study preferred red to any other color. It was further observed that preference tended to change with an advance in grade level. With increased chronological and mental age of the children, red lost its preferential position to both blue and yellow. The order of preference for the entire sample was red, blue, yellow, green, orange, and purple. Boys seemed to have more distinct preferences among colors than girls.

With these theoretical implications from the literature, the group proceeded to choose a sample and to develop a method which could be used to extract data. 


\section{CHAPTER II}

\section{METHODOLOGY}

General methodology of the study followed from considerations that the study intended to be both exploratory and designed to test the reliability of inferences drawn from pictures collected for other purposes. The literature was searched for hypotheses relating to sexual and developmental characteristics which could be tested. A sample of 300 pictures out of 481 found useable in a much larger population was studied by means of a pretested schedule. Statistical tests of the hypotheses and of reliability were the principal bases for conclusions. Details of the general methodology follow.

\section{POPULATION AND SAMPLE}

Since the name and grade of the artist could be obtained only from the original pictures and not from the transparencies, the pictures were examined at the office of the E. C. Brown Trust Foundation where they were stored. Those pictures that met all the following criteria were selected for the sampling:

1. Grade level of the artist could be identified.

2. Sex of the artist could be identified. 
3. The drawings were executed with crayon or poster paint. Only first through third grade drawings were included in the sample. Fourth grade drawings and those from ungraded classes were eliminated because of the small number of drawings available from the se groups.

Sex of the artist was determined by the name on the picture. Those pictures without names and those with names that were not clearly identifiable as male or female were eliminated. Finger paintings, collages, pencil drawings, and chalk drawings were also eliminated. After sorting the original pictures to select the population, the pictures were stored and further viewing was from transparencies. The samples for the pretests and the final study were selected from the 481 pictures which met all of the above criteria. Each picture had been assigned a number by the E. C. Brown Trust Foundation. These numbers were retained by this study for identification purposes. Each of the 481 pictures which met the criteria for this study was recorded by number on a five by eight card.

The group decided to choose separate pictures rather than the same pictures so that the sample would be larger. After eliminating cards representing pictures used in the pretests, the remaining cards were separated into six groups, i. e., male and female of first, second, and third grade. Each observer shuffled a deck of cards 
until they were well mixed. He then chose ten cards at random. The picture numbers were recorded sequentially on a list and the cards then returned to the deck. This procedure was followed by each observer with each deck. The resulting five lists of sixty pictures each were then exchanged among the observers so that memory could not affect judgments. The total of 300 choices represented 241 pictures. Of the fifty-nine pictures which had been chosen by more than one observer, forty-eight were chosen by two observers, and eleven were chosen by three observers.

\section{SCHEDULE AND HYPOTHESES}

Many questions for possible exploration were raised by the group in the beginning phase of the study. These questions were related to concepts found in the literature, personal observation, and experience of the group members. Theories about behavior and development were discussed and characteristics were selected from these theories to be identified in the children's art. Concepts included those found in the fields of psychology and art education.

Psychological and socio-economic correlates of the art.in the sample could not be studied due to lack of information about the artists. Therefore, the group selected for investigation those areas which could be considered dependent on the two variables, sex and grade level. Sixty-nine items were selected for analysis from a 
much larger number of possible characteristics. The hypotheses related to theoretical and observed differences in the art of males and females, and developmental differences observed between the first, second, and third grades.

A schedule outlined operationalized concepts suggested in the first chapter, and is reproduced in Appendix B. Items on the schedule were defined in the following ways:

Items one through three relate to orientation; that is, placement of forms in relationship to the format of the picture. Orientation operationalizes the Eriksonian (1, pp. 102-106) concepts of towers, upward movement, intrusion, and enclosure. The items Vertical, Circular, and Other indicate the general orientation of the picture. Vertical is defined as either a predominance of perpendicular objects in the picture or an overall perpendicular effect. Trees, towers, and tall buildings are indices. Circular indicates either a predominance of circular objects in the picture or an overall circular effect. Fetuses in utero and clouds are also indicative of Circular. If pictures are not notably Vertical or Circular, they are classified as Other.

Based on Eriksonian theory, it is hypothesized that the Vertical of males is greater than the Vertical of females. It is also hypothesized that the Circular of males is less than the Circular of females. 
$\mathrm{H} \mathrm{1:} \mathrm{Vm}>\mathrm{Vf}$

$\mathrm{H} \mathrm{2:} \mathrm{Cm}<\mathrm{Cf}$
Ho $1: \mathrm{Vm}=\mathrm{Vf}$

Ho 2: $\mathrm{Cm}=\mathrm{Cf}$

Items four through six relate to space. This category operationalizes the Eriksonian (1, pp. 103-105) concept that the sex of the child is related to the use of enclosure. The items in the category of Space include Open, Closed, and Indeterminate. An Open picture is defined as one without boundaries on all sides. The edge of the paper is not considered a boundary. A Closed picture is defined as one with boundaries on all sides, usually a frame or border. A single building or a single person, free floating in the center of the paper is Indeterminate by definition. A single person or single building on a baseline is identified as Open. It was hypothesized that the Open of males is greater than the Open of females. It was further hypothesized that the Closed of males is less than the Closed of females.
H 3: Om $>$ Of
Ho 3: Om $=$ Of
$\mathrm{H}$ 4: $\mathrm{Cm}<\mathrm{Cf}$
Ho 4: $\mathrm{Cm}=\mathrm{Cf}$

Items seven through nine relate to dimension in terms of a baseline. Baseline is observed by Gaitskell (2, p. 136) as being related to a child's concept of reality and as a developmental skill. The items on the schedule are Baseline Shown, Baseline Implied, and Baseline Absent. Baseline Shown is defined as having a drawn baseline. If the edge of the paper is used as a baseline, it is 
identified as Baseline Implied. If figures are arranged as if there were a baseline, the picture is identified as Baseline Implied. If there is no baseline shown or implied it is identified as Baseline Absent. It was hypothesized that the use of baseline is inversely related to grade.

$$
\text { H 5: } \mathrm{B}_{1}<\mathrm{B}_{2}<\mathrm{B}_{3} \quad \text { Ho 5: } \mathrm{B}_{1}=\mathrm{B}_{2}=\mathrm{B}_{3}
$$

Items ten through twenty-one relate to the number and sex of the people in the pictures. These items are self-explanatory and operationalize Gaitskell's (2, p. 135) observation that there is a sex difference in the use of people, girls using people more often than boys in their art. Also operationalized is Horovitz' (9, p. 113) observation that boys draw fewer females than girls draw, and girls draw fewer males than boys draw. The $x$-ray people pictured are included with $\mathrm{x}$-ray structures for statistical analysis and are discussed in a later section. It was hypothesized that the mean number of People drawn by males is less than the mean number of People drawn by females. It was hypothesized that Females drawn by males is less than Females drawn by females. It was hypothesized that

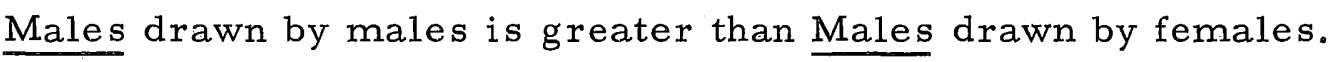
H 6: $\overline{\mathrm{XP}}<\overline{\mathrm{X}} \mathrm{Pf}$
Ho 6: $\overline{\mathrm{X}} \mathrm{Pm}=\overline{\mathrm{X}} \mathrm{Pf}$
$H 7: F m<F f$
Ho 7: $F \mathrm{~m}=\mathrm{Ff}$
$\mathrm{H}$ 8: $\mathrm{Mm}>\mathrm{Mf}$
Ho 8: $\mathrm{Mm}=\mathrm{Mf}$ 
Items twenty-two through twenty-six related to projected concepts of reproduction. As children grow older they become more knowledgeable about reproduction. Hence it is reasoned that the younger the child, the less scientific his concepts. The item

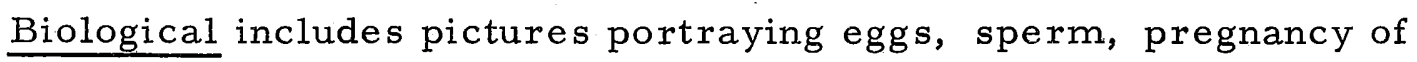
mothers, and fetuses in utero. The item Cultural categorizes the pictures showing hospitals, ambulances, baby nurseries, and medical personnel. The item Religious identifies those pictures which suggest religious concepts of reproduction and includes the pictures portraying heaven, God, angels, and miracles. The item Folk includes pictures portraying mythical concepts such as the stork and the cabbage patch. It was hypothesized that the incidence of biological reproductive concepts in the pictures increases with grade in school. Conversely, the incidence of non-biological concepts decreases with grade.

In surveying the literature no references were found concerning children's concepts of reproduction. However, for purposes of this study, it was assumed that since our culture promotes female identification with the nurturing role through play and culturally assigned toys, exploratory hypotheses could be developed relating reproductive concepts with the sex of the child. It was hypothesized that Folk and Religious pictures of males is greater than Folk and $\underline{\text { Religious pictures of females, and that Cultural and Biological }}$ 
pictures of males is less than the Cultural and Biological pictures of females.
H 9: $\mathrm{B}_{1}<\mathrm{B}_{2}<\mathrm{B}_{3}$
Ho 9: $B_{1}=B_{2}=B_{3}$
H 10: FRm $>$ FRf
Ho 10: $F R m=F r f$
H 11: $\mathrm{CBm}<\mathrm{CBf}$
Ho $11: \mathrm{CBm}=\mathrm{CBf}$

Items twenty-seven through twenty-nine relate to the number and type of animals. Gaitskell (2, p. 135) and Erikson (1, pp. 105106) observe that a sex difference occurs in depicting animals. The item Birds includes all birds including storks and simple line drawings. The item Pets includes dogs, cats, and other animals normally considered pets. The item Other includes animals other than those listed above. It was hypothesized that the total number of Animals used by males is greater than the total number of Animals used by females.
H 12: Am > Af
Ho 12: $\mathrm{Am}=\mathrm{Af}$

Items thirty through thirty-three relate to the use of structures. Erikson (1, p. 107) suggests there is a sex difference in portrayal of exteriors and interiors. This study suggests that the use of $x$-ray is related to the Eriksonian concepts of "open" and "closed," referred to in the discussion of items four through six. Lowenfeld (8, p. 127), Gaitskell (2, pp. 138-139), and Horovitz (9, p. 57) also make reference to $x$-ray techniques. Structures are classified as Houses, Buildings, or Indeterminate. Interior, Exterior, or 
$\underline{\mathrm{X}-\mathrm{ray}}$ are the sub-categories for House and Building. House is defined as a single family dwelling. Building is any structure, other than a house, with an identifiable function. The category Indeterminate is included for those structures which could not be identified by function. The Structures $X$-raypictures are combined with the People X-ray pictures for purposes of this study. The categories of $\underline{X-r a y}$ Buildings, $\underline{X-r a y ~ H o m e s, ~ a n d ~} \underline{X-R a y ~ P e o p l e ~ w e r e ~ i n c l u d e d ~}$ to further operationalize Erikson's concept of the use of enclosure by females. It was hypothesized that the use of $x$-ray techniques by males is less than the use of $x-r a y$ techniques by females.

It was hypothesized that the Exterior portrayals by males is greater than the Exterior portrayals of females. It was further hypothesized that the Interior portrayals by males is less than the Interior portrayals by females. Because a female role is to identify with the home and a male role is to identify with the world outside the home, it was hypothesized that the number of Houses drawn by males is less than the number of Houses drawn by females. It was hypothesized that the number of Buildings drawn by males is greater than the number of Buildings drawn by females.
H 13: $\operatorname{Em}>$ Ef
Ho 13: $\operatorname{Em}=\mathrm{Ef}$
H 14: $\operatorname{Im}<$ If
Ho 14: $\operatorname{Im}=$ If
H 15: $\mathrm{Hm}<\mathrm{Hf}$
Ho 15: $\mathrm{Hm}=\mathrm{Hf}$
$\mathrm{H}$ 16: $\mathrm{Bm}>\mathrm{Bf}$
Ho 16: $\mathrm{Bm}=\mathrm{Bf}$ 
H 17: $X$-ray $m<X-r a y ~ f$ Ho 17: $\mathrm{X}$-ray $\mathrm{m}=\mathrm{X}-$ ray $\mathrm{f}$

Items thirty-four through forty-two relate to objects in pictures other than people, structures, and animals. These items are grouped together to facilitate the use of the schedule although they represent different areas of investigation. Trees, Smoke, Paths,

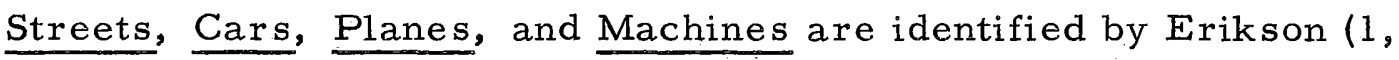
p. 102) and Gaitske11 (2, p. 135) as associated with masculine identification. Smoke, Paths, and Streets operationalize upward movement. Cars, Planes, and Machines represent mechanical objects which are masculine. Closed Doors relates to Erikson's (1, p. 105) enclosure concept and are considered feminine. Open Doors are considered masculine. Furniture and Clouds are associated by Erikson (1, p. 104) with feminine identification. Eggs and Sperm are associated with scientific concepts and are related to the knowledge held by the child. Eggs are as sociated with the circular concept of feminine identification referred to by Erikson (1, p. 106).

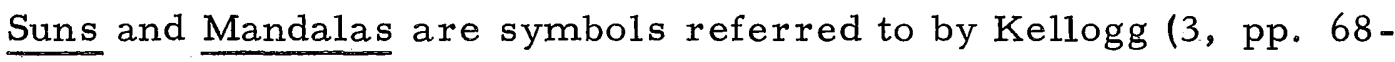
89) as having developmental significance. For the purpose of this study mandalas are decorative figures consisting of circles with lines cutting through them. Suns and Mandalas further operationalize the feminine circular or enclosure concept. It was hypothesized that the number of masculine objects, items thirty-four, thirty-five and: thirty-seven, by males is greater than the number of 
masculine objects by females. It was further hypothesized that the number of feminine objects, items thirty-six and forty-two, by males is less than the number of feminine objects by females.

H 18: $\mathrm{MOm}>\mathrm{MOf}$ Ho 18: $\mathrm{MOm}=\mathrm{MOf}$

H 19: $F O m<F O f$ Ho 19: $F O m=F O f$

Items forty-three through forty-seven related to aspects of elaboration. Elaboration is an Eriksonian (1, p. 105) concept related to feminine roles and is operationalized by examining the categories of Marked Detail of People, Marked Detail of Picture, and Ornamentation. Marked Detail of People is manifested by the detailing of figure drawing. The inclusion of fingers, ornaments such as hair bows, or detailed clothing is a 1 s o Marked Detail of People. Marked Detail of Picture related to the inclusion of furniture, trees, flowers, birds, clouds, and other objects unrelated to the theme of the picture. Ornamentation is defined as non-objective drawing in the picture such as borders, designs, and colors used without relation to the content of the picture. Gaitskell (2, p. 142) makes reference to marked care of execution and marked symmetry as feminine traits. Marked Care of Execution is a function of the precision displayed by the artist. Marked Symmetry is defined as a repetition of objects on either side of an imaginary centerline, or the positioning of a balanced single object in the center of the picture. This definition excludes the concept of balance, the placement 
of equal mass on either side of the picture. It was hypothesized that the Elaboration by males is less than the Elaboration by females. H 20: $\mathrm{Em}<\mathrm{Ef}$ Ho 20: $\mathrm{Em}=\mathrm{Ef}$

Items forty-eight through fifty-three relate to tonality and intensity of color. Burns' (6, p. 129) research leads us to hypothesize that females tend to use light and delicate colors and males tend to use dark and bold colors. These concepts describe the use of color. Tonality relates to the preponderance of hues chosen: Light Colors are red, yellow, orange, pink, and white; Dark Colors are blue, green, purple, brown, and black. When there is no predominance of either Light Colors or Dark Colors, tonality is considered Indeterminate. Intensity of color describes the pictures in terms of Bold or Delicate and is generally determined by the pressure of the crayon. It was hypothesized that the employment of Light Color by males is less than the employment of Light Color by females. It was hypothesized that the employment of Dark Color by males is greater than the employment of Dark Color by females. It was hypothesized that the employment of Delicate Color by males is less than the employment of Delicate Color by females. It was hypothesized that Bold Color of males is greater than Bold Color of females. 
H 21: $\operatorname{Lm}<\mathrm{Lf}$

H 22: $\mathrm{Dm}>\mathrm{Df}$

H 23: Del. $m<$ Del. $f$

$\mathrm{H}$ 24: $\mathrm{Bm}>\mathrm{Bf}$
Ho 21: $L \mathrm{~m}=\mathrm{Lf}$

Ho 22: $\mathrm{Dm}=\mathrm{Df}$

Ho 23: Del. $m=$ Del.f

Ho 24: $\mathrm{Bm}=\mathrm{Bf}$

Items fifty-four through sixty-five relate to color. The category Color is included on the schedule in order to test Horovitz' (9, p. 92) observation that the younger the child, the more colors he uses in his picture. It also provides data for testing the observation that the mean number of colors used is related to the sex of the child. Colors identified are Red, Yellow, Orange, Green, Blue, Violet, Brown, Black, White, and Pink. Even minute amounts were recorded if used in a picture. Flesh colors and shades of aqua were marked to the closest equivalent; Pink, Orange, or Brown in the case of flesh color, and Blue or Green in the case of aqua. It was hypothesized that first grade children use a greater mean number of colors than second grade children; and second grade children use a greater mean number of colors than third grade children use. It is also hypothesized that males use a smaller mean number of colors than females use.

$$
\begin{array}{ll}
\text { H 25: } \overline{\mathrm{X}} \mathrm{C}_{1}>\overline{\mathrm{X}} \mathrm{C}_{2}>\overline{\mathrm{X}} \mathrm{C}_{3} & \text { Ho 25: } \overline{\mathrm{X}} \mathrm{C}_{1}=\overline{\mathrm{X}} \mathrm{C}_{2}=\overline{\mathrm{X}} \mathrm{C}_{3} \\
\text { H 26: } \overline{\mathrm{X}} \mathrm{Cm}<\overline{\mathrm{X}} \mathrm{Cf} & \text { Ho 26: } \overline{\mathrm{X}} \mathrm{Cm}=\overline{\mathrm{X}} \mathrm{Cf}
\end{array}
$$

Items sixty-eight and sixty-nine relate to the background of the picture. Gaitskell (2, p. 136-137) refers to filling in of 
background as a developmental trait. It is hypothesized that the first graders fill in backgrounds in fewer instances than do second graders; and second graders fill in background in fewer instances than do third graders.

H 27: $\mathrm{FI}_{1}<\mathrm{FI}_{2}<\mathrm{FI}_{3} \quad$ Ho 27: $\mathrm{FI}_{1}=\mathrm{FI}_{2}=\mathrm{FI}_{3}$

Items sixty-six and sixty-seven are included on the schedule for two purposes. The first is to determine whether judges can estimate the grade and sex of the artist using factors listed on the schedule. The second purpose is to see if the factors influencing this estimation can be isolated and ranked according to amount of influence. No hypotheses for these categories are included although the ability of social workers to make correct judgments is perhaps the most important implication of this study. It was originally hypothesized by the group that through the use of the factors on the schedule, the sex and the grade of the artist could be correctly es timated. The validity of the factors and the reliability of the judgments effected the estimates of grade and sex. The purpose of these categories was to evaluate the total use of factors to make judgments. The ability to estimate age and sex correctly is measured and the results are given in the next chapter. 


\section{PRETESTS}

Two pretests were made to test the schedule and measure the reliability of judgment. For the first pretest thirty pictures were selected at random from the population. The observers viewed and judged the same pictures independently. After the first pretest, results were evaluated. Several categories on the schedule were eliminated because they were not represented in the sample, or because in the process of refining the definition the observers could not reach consensus. The following categories were eliminated: Perspective, Temporal Duration, and Outline or Solid because they were inappropriate, not being present in the sample; and Artistic Impact and Color Impact because the observers could not reach consensus on definition. Following the first pretest the categories of Elaboration, Tonality, and Intensity of Color were added.

Twenty pictures were viewed and judged independently for the second pretest. The two pretests measured reliability and aided in refining the items on the schedule where reliability had to be improved.

The pretests also provided training for the observers. The observers were trained in several ways. More than forty hours were spent defining and refining the items on the schedule prior to the first pretest until consensus was reached on the definition of each 
item. The first pretest revealed that more refining was needed. More time was spent until consensus was again reached through group process. The second pretest gave additional training to the observers.

Tests of hypotheses were based on Chi Square, tests of proportions and $T$ ratios. Several tests of agreement, variance, concordance, and reliability were tried; that which was considered most appropriate will be reported for each instance. Descriptive and inferential statistics with their implications will be presented in the next chapter. 


\section{CHAPTER III}

\section{FINDINGS}

The data collected from the schedule were evaluated using the methods described above. The findings are reported in the approximate order in which they were presented in the preceding section, Schedule and Hypotheses. In each case the hypothesis number is the same. If a hypothesis is not numbered, it indicates that it was developed during the analysis. Some null hypotheses were rejected by observation and are discussed in the text but not included by number.

All items on the schedule were evaluated for reliability of judgments by computing percentages of agreement among the observers. Twenty pictures were used for the pre-test. The same pictures were viewed by the five judges. Neither prior to nor during the viewing was there discussion of the picture by the observers. The data collected were compared for percentages of agreement. Ninety percent agreement was used as an acceptable standard of reliability. A proportions test was used to compare the percentages on the pre-test to the $90 \%$ standard. Thus percentages below $90 \%$ were considered reliableif the deviation on a one tail test was less 
than 1.96 standard deviations. These percentages are summarized in Table I.

TABLE I

PERCENTAGE OF AGREEMENT BY OBSERVERS ON PRETEST

\begin{tabular}{lc}
\hline Category & $\begin{array}{c}\text { Percent of } \\
\text { agreement }\end{array}$ \\
\hline Orientation & 84 \\
Space & 92 \\
Dimensions & 94 \\
People & 76 \\
Reproduction & 88 \\
Animals & 80 \\
Structures & 84 \\
Objects & 89 \\
Elaboration & 68 \\
Tonality & 71 \\
Color & 91 \\
Background & 88 \\
\hline
\end{tabular}

The categories of Tonality, Elaboration, and People were not considered reliable on the pretest. These categories were discussed and redefined prior to the final test in an effort to improve agreement. The other categories were not found to be significantly different from $90 \%$ and were acceptable for this study.

The $z$ score (11) as used here is a measure of the number of standard deviations from the:percentage of agreement expected to occur by chance. A z score of 2.58 or greater would occur by chance less than one time in 100 . These scores provide a means 
for comparing the relative reliability of the categories.

Data were gathered for the final test and the percentages of agreement were compared to those of the pretest. Of the 300 pictures in the sample forty-eight were viewed by two judges and eleven were viewed by three judges. Different processes were used for selecting the samples to measure reliability in the pretest and in the final test. Therefore the percentage scores could not be considered comparable. When five judges view a category with three possible choices, there is a $40 \%$ minimum agreement. When two judges view the same category, there is either $100 \%$ agreement or $100 \%$ disagreement. Thus disagreements on the final test had greater effect than disagreements on the pretest.

In order to make scores more comparable, a proportions test was used and $\mathrm{z}$ scores calculated. For the pretest, $\mathrm{z}$ scores were used to measure the difference from the minimum possible agreement; in the final test the $\mathrm{z}$ score is a measure of the variation from the chance probability of agreement. The $z$ scores and percentages are shown in Table II. $Z$ scores were not computed for those percentages in the final test that could be judgedreliable by observation.

In most instances agreement was reduced over the final observation with the larger population and corresponding larger variance expected. In general, the more complicated or abstract the item to be judged, the lower was agreement. Reliability of judges was low 
for scientific purposes, and results of tests of hypotheses should be accepted accordingly.

TABLE II

COMPARISON OF PERCENTAGES OF AGREEMENT AND z SCORES FOR PRETEST AND FINAL TEST

\begin{tabular}{|c|c|c|c|c|}
\hline \multirow[b]{2}{*}{ Category } & \multicolumn{2}{|c|}{ Pre-test } & \multicolumn{2}{|c|}{ Final Test } \\
\hline & $\begin{array}{c}\% \text { of } \\
\text { agreement }\end{array}$ & $\begin{array}{c}z \\
\text { score }\end{array}$ & $\begin{array}{c}\% \text { of } \\
\text { agreement }\end{array}$ & $\begin{array}{c}z \\
\text { score }\end{array}$ \\
\hline Orientation & 84 & 11.8 & 74 & 10.7 \\
\hline Space & 92 & 15.5 & 74 & 10.7 \\
\hline Dimensions & 94 & 22.5 & 81 & 14.1 \\
\hline People & 76 & 13.0 & 83 & 42.9 \\
\hline Reproduction & 88 & 20.3 & 78 & 16.0 \\
\hline Animals ${ }^{1}$ & 80 & --- & 98 & --- \\
\hline Structures & 84 & 10.8 & 70 & 13.7 \\
\hline Objects $^{2}$ & 89 & --- & 82 & $-\ldots$ \\
\hline Elaboration ${ }^{2}$ & 68 & --- & 56 & --- \\
\hline Tonality & 71 & 6.9 & 58 & 5.3 \\
\hline Inten sity & -- & ---- & 48 & 3.4 \\
\hline Color ${ }^{2}$ & 91 & $-\ldots$ & 89 & $-\cdots$ \\
\hline Background & 88 & 8.8 & 92 & 18.2 \\
\hline
\end{tabular}

${ }^{1}$ Due to the low incidence of animals in the pictures, no other statistical evaluation is made of this category.

2 z scores were not calculated for those categories where more than one response could be made.

\section{EVALUATION}

Chi-squares, t-tests, and percentages were used to evaluate the data. The plethora of data made it unfeasible to isolate all the factors on the schedule or to calculate all the possible combinations 
of factors. The statistics reported below relate to the hypotheses of this study. In addition, findings are included that indicate some areas meriting further investigation.

The first group of data analyzed here is that relating to Eriksonian concepts. It was predicted that males produce pictures which would be judged vertical, while females produce pictures that would be judged circular. It was found in this sample that there was no significant difference in the method in which males and females drew their pictures. Of the 300 pictures, 219 could be judged neither vertical nor circular.

$\mathrm{H} 1: \mathrm{Vm}>\mathrm{Vf}$

H. 2: $\mathrm{Cm}<\mathrm{Cf}$ $\mathrm{Chi}^{2}=.100$ d. f. $=1, p>.05$

Ho accepted

The use of space in pictures is another Eriksonian concept tested. It was predicted that males produce predominantly open pictures and females produce predominantly enclosed pictures. Of the 300 pictures in this study, 214 were judged open. No significant difference by sex was found in this category, nor was there any significant difference found in the eighty-six pictures judged closed or indeterminate.

H 3: Om > Of

$\mathrm{H}$ 4: $\mathrm{Cm}<\mathrm{Cf}$

$\mathrm{Chi}^{2}=.034$
Ho 3: $\mathrm{Om}=\mathrm{Of}$

Ho 4: $\mathrm{Cm}=\mathrm{Cf}$

d. f. $=1, p>.05 \quad$ Ho accepted 
The concepts of openness and enclosure were further tested by two additional hypotheses. A comparison was made among the items of Interior, Exterior, and $\underline{X-r a y}$ (People and Structures). It was predicted that if females used enclosures, they would also use interiors and $x$-ray technique more often than males.
H 13: Em $>$ Ef
Ho 13: $\mathrm{Em}=\mathrm{Ef}$
H 14: Im $<$ If
Ho 14: $\operatorname{Im}=$ If
$\mathrm{Chi}^{2}=1.09$
d. f. $=1, p>.05$
Ho accepted

By observation differences in the use of $x$-ray were not significant.

It was predicted that the use of baseline in children's art would vary by grade. A significant difference was found.
H: $B_{1}<B_{2}<B_{3}$
Ho 5: $\mathrm{B}_{1}=\mathrm{B}_{2}=\mathrm{B}_{3}$
$\mathrm{Chi}^{2}=10.92$
d. $f_{0}=2, p<.05$
Null hypothesis rejected.

The first and the third graders tended to use baselines or implied baselines. The second graders tended to use either implied baselines or not to use baselines. Forty-four of the ninety-six pictures not showing or implying baselines were produced by second graders. From this data then, an alternative hypothesis was derived:

$$
\mathrm{H}: \mathrm{B}_{1}>\mathrm{B}_{2}<\mathrm{B}_{3}
$$

The use of baselines in the first grade is greater than the use of baselines in the second grade; the use of baselines in the second grade is less than in the third grade. 
Horovitz' observation that children tend to draw people of their own sex was examined. It was predicted that of the males drawn, more would be drawn by males than by females. It was further predicted that of the females drawn, more would be drawn by females than by males. Of the 168 people drawn that could be identified by sex, eighteen were males and 150 were females. Ten of the males were drawn by males, eight by females; eighty-seven of the females were drawn by females, sixty-three by males. There was no difference in the proportion of male figures drawn by males or females nor in the proportion of female figures drawn by males and females.
$\mathrm{H} 7: \mathrm{Fm}<\mathrm{Ff}$
Ho 7: $F \mathrm{~m}:=\mathrm{Ff}$
$\mathrm{H}$ 8: $\mathrm{Mm}>\mathrm{Mf}$
Ho 8: $\mathrm{Mm}=\mathrm{Mf}$

$$
\mathrm{Chi}^{2}=1.12
$$
d. f. $=1, p>.05$
Ho accepted

Gaitskell observed that females draw more people than males draw. The data were controlled for sex and the mean number of people portrayed was calculated. One picture, viewed by two observers, depicted a hospital nursery with more than twenty-seven people in it. Since that number would have had an abnormal effect on the mean, the picture was eliminated. Pictures without people were also eliminated. T tests were used to test the significance of differences found. 
TABLE III

MEAN NUMBER OF PEOPLE DEPICTED IN SAMPLE

\begin{tabular}{cccc}
\hline & Male & & Female \\
Grade & $\overline{\mathrm{X}}$ & Grade & $\overline{\mathrm{X}}$ \\
\hline 1 & 2.05 & 1 & 2.44 \\
2 & 1.76 & 2 & 1.75 \\
3 & 1.70 & 3 & 1.45 \\
\hline
\end{tabular}

When the means were controlled by sex, no difference was found in the number of people depicted.

$$
\mathrm{H} \text { 6: } \overline{\mathrm{X}} \mathrm{Pm}<\overline{\mathrm{X}} \mathrm{Pf} \quad \text { Ho 6: } \overline{\mathrm{X}} \mathrm{Pm}=\overline{\mathrm{X}} \mathrm{Pf}
$$

Ho accepted by observation.

Although no hypotheses were formulated concerning difference in numbers of people shown by grade, significant differences were found between first and second graders, and between first and third graders. This relationship between grades was tested using a $\mathrm{T}$ test and found to be significant at the .05 level.

$$
\begin{array}{lll}
\text { Ho: } P_{1}=P_{2} & T=2.38 & \text { d. f. }=p<.05 \\
& \text { Ho rejected } & \\
\text { Ho: } P_{1}=P_{3} & T=3.11 & \text { d. f. }=p<.05 \\
& \text { Ho rejected } &
\end{array}
$$

Table IV further illustrates differences of $T$ values for all the combinations when the $T$ values for each grade and sex are com:pared. In this table any $\mathrm{T}$ value greater than 1.96 is considered 
significant. These values would occur by chance less than five times in 100. In this sample the first grade females have the largest effect on the outcome of the data.

TABLE IV

VALUES OF COMPARISONS BETWEEN GRADE AND SEX OF THE NUMBER OF PEOPLE PORTRAYED

\begin{tabular}{|c|c|c|c|c|c|}
\hline & $2 \mathrm{M}$ & $3 \mathrm{M}$ & $1 F$ & $2 F$ & $3 F$ \\
\hline $1 \mathrm{M}$ & .94 & 1.09 & 1.06 & .94 & 2.00 \\
\hline $2 \mathrm{M}$ & & .78 & 3.34 & .05 & .45 \\
\hline $3 \mathrm{M}$ & & & 2.47 & .75 & 1.39 \\
\hline $1 F$ & & & & 2.22 & 3.54 \\
\hline $2 F$ & & & & & .75 \\
\hline
\end{tabular}

Some objects were defined as masculine and other defined as feminine. It was expected that some objects would be examples of Eriksonian concepts. It was also expected that other objects would be used because of socially determined conventions. Male objects were drawn primarily by males, but there was little difference in the depiction of female objects by males or females. On the schedule $_{8}$ Trees were considered male objects portraying the Eriksonian concept of upward thrust. Of the forty trees drawn, however, twenty-three were drawn by females. If Trees were eliminated from 
those objects considered male, the differences would be significant in the direction hypothesized.

$$
\begin{array}{ll}
\text { H 18: MOm }>\text { MOf } & \text { Ho 18: MOm = MOf } \\
\text { H 19: FOm > FOf } & \text { Ho 19: FOm }=\text { FOf } \\
C^{2}{ }^{2}=4.80 & \text { d. f. }=1, p<.05 \quad \text { Ho rejected. }
\end{array}
$$

The use of Elaboration was found to be determined largely by the sex of the artist. In all grades the females were judged to elaborate more than males. The use of elaboration by females was significantly greater than its use by males. The incidence of elaboration is summarized in Table V.

TABLE V

INCIDENCE OF ELABORATION

\begin{tabular}{llllll}
\hline $1 \mathrm{M}$ & $2 \mathrm{M}$ & $3 \mathrm{M}$ & $1 \mathrm{~F}$ & $2 \mathrm{~F}$ & $3 \mathrm{~F}$ \\
\hline 29 & 22 & 30 & 43 & 32 & 64
\end{tabular}

$\mathrm{H} \mathrm{20:} \mathrm{Em}<\mathrm{Ef}$

Ho 20: $\mathrm{Em}=\mathrm{Ef}$

$\mathrm{Chi}^{2}=15.28$

d. f. $=1, p<.05$ Ho rejected

A significant difference in the use of Elaboration among the grades was also found. This difference is attributed to a decreased use of Elaboration in the second grade and an increased use in the third grade. Although no hypotheses were formulated from the reading or in the methodology chapter, a tentative hypothesis was tested 
as follows:

$$
\begin{gathered}
\text { Ho: } E_{1}=E_{2}=E_{3} \\
\text { Chi }^{2}=10.40 \quad \text { d.f. }=1, p<.05 \text { Ho rejected }
\end{gathered}
$$

Tonality was controlled for sex and was judged to be predominantly Dark Colors or Indeterminate. Sixteen percent of the pictures were judged to have used light colors, $48 \%$ dark colors, and $36 \%$ were indeterminate. There was no significant difference by sex of those artists judged to use Light Color or those judged to use Dark Color. The preference for Tonality is, in this sample, Dark Colors.

$$
\begin{array}{lr}
\text { H 21: Lm Lf } & \text { Ho 21: Lm }=\text { Lf } \\
\text { H 22: Dm }>\text { Df } & \text { Ho 22: Dm }=\text { Df } \\
\text { Chi }^{2}=1.95 & \text { d. f. }=1, p>.05 \text { Ho accepted. }
\end{array}
$$

When Intensity was controlled for sex, a significant difference was found. The percentages were more equally distributed for Intensity than for Tonality. Thirty percent of the pictures viewed were judged to use Delicate colors, $43 \%$ Bold, and $27 \%$ Indetermi nate. The preference of males is for Bold Color; that of females is for Delicate Color.

H 23: Del. $\mathrm{m}<$ Del. $\mathrm{f}$

$\mathrm{H}$ 24: $\mathrm{Bm}>\mathrm{Bf}$

$\mathrm{Chi}^{2}=5.49$
Ho 23: Del. $m=$ Del. $f$

Ho 24: $\mathrm{Bm}=\mathrm{Bf}$

d. f. $=1, p<.05$ Ho rejected. 
The mean number of colors employed was measured by $\mathrm{T}$ tests. The means are listed in Table VI. The colors used most often were tabulated but were not subjected to any tests of significance. The colors most frequently used were, in order of preference, Black,

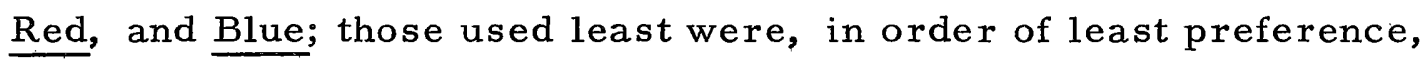
White, Pink, and Purple.

TABLE VI

MEAN NUMBER OF COLORS USED BY GRADE AND SEX

\begin{tabular}{lllllll}
\hline \hline $1 M$ & $2 M$ & $3 M$ & $1 F$ & $2 F$ & $3 F$ \\
\hline
\end{tabular}
4.32
4. 16
4.62
5.42
4. 26
5.42

As the means suggest, the $\mathrm{T}$ scores indicate a significant difference between the first and second grades, and the third and second grades. Therewas no significant difference between the first and third grades.

$$
\begin{array}{llll}
\text { H 25: } & \overline{\mathrm{X}} \mathrm{C}_{1}>\overline{\mathrm{X}} \mathrm{C}_{2}>\overline{\mathrm{X}} \mathrm{C}_{3} & \text { Ho } 25: \overline{\mathrm{X}} \mathrm{C}_{1}=\overline{\mathrm{X}} \mathrm{C}_{2}=\overline{\mathrm{X}} \mathrm{C}_{3} \\
\text { Ho } \quad \overline{\mathrm{X}} \mathrm{C}_{1}=\overline{\mathrm{X}} \mathrm{C}_{2} & \mathrm{~T}=2.75 & \text { d.f. }=\infty \quad \text { Ho rejected. } \\
\text { Ho } \quad \overline{\mathrm{X}}_{3}=\overline{\mathrm{X}} \mathrm{C}_{2} & \mathrm{~T}=3.79 & \text { d.f. }=\infty \quad \text { Ho rejected. } \\
\text { Ho } \quad \overline{\mathrm{X}} \mathrm{C}_{1}=\overline{\mathrm{X}} \mathrm{C}_{3} & \mathrm{~T}=.65 \text { d.f. }=\infty \quad \text { Ho accepted. }
\end{array}
$$

No significant difference at the .05 level is found in the use of Color by males and females. However, the null hypothesis would be rejected at the 10 level of significance and the rejection of the hypotheses should be considered inconclusive. 


$$
\begin{array}{rlrl}
\text { H 26: } \overline{\mathrm{X}} \mathrm{Cm}<\overline{\mathrm{X}} \mathrm{Cf} & \text { Ho 26: } \overline{\mathrm{X}} \mathrm{Cm}=\overline{\mathrm{X}} \mathrm{Cf} \\
\mathrm{T}=1.89 & \text { d.f. }=\infty & \text { Ho accepted. }
\end{array}
$$

The $T$ scores for all combinations of grade and sex are given in

Table VII. Those values over 1.96 indicate a significant difference.

TABLE VII

T SCORES FOR THE DIFFERENCES IN THE MEAN NUMBER

\begin{tabular}{|c|c|c|c|c|c|}
\hline & $2 \mathrm{M}$ & $3 \mathrm{M}$ & $1 F$ & $2 F$ & $3 F$ \\
\hline $1 \mathrm{M}$ & .5161 & 1.00 & 3.33 & .17 & 3.64 \\
\hline $2 \mathrm{M}$ & & 2.50 & 3.60 & .27 & 3.82 \\
\hline $3 \mathrm{M}$ & & & 2.35 & 1.00 & 2. 50 \\
\hline $1 \mathrm{~F}$ & & & & 3.05 & $--\infty$ \\
\hline $2 \mathrm{~F}$ & & & & & 3.22 \\
\hline
\end{tabular}
OF COLORS USED BY GRADE AND SEX

The data on Background were used as a measure of sequential development. The hypothesis states that first graders fill in backgrounds less than third graders. This was found to be true. The most change occurs between second and third grade. First graders filled in background $19 \%$ of the time, second graders $27 \%$, and third graders $62 \%$. There is no difference between males and females in the use of filled in backgrounds. 
H 27: $\mathrm{FI}_{1}<\mathrm{FI}_{2}<\mathrm{FI}_{3} \quad$ Ho 27: $\mathrm{FI}_{1}=\mathrm{FI}_{2}=\mathrm{FI}_{3}$ $\mathrm{Chi}^{2}=45.39 \quad$ d. f. $=2, \mathrm{p}<.05$ Ho rejected.

The content of the pictures was tested for differences in the portrayal of concepts of reproduction. By observation it was found that there are no differences exhibited by sex. When the data are examined by grade level, significant differences are found. The Folk and Religious items were eliminated since there were too few incidences to be computed. Since one picture could exhibit more than one concept of reproduction, the number of concepts exceeds 300. (Table VIII)

TABLE VIII

NUMBER OF PERSONS USING SELECTED CONCEPTS OF REPRODUCTION BY GRADE

\begin{tabular}{lccc}
\hline & First & Second & Third \\
\hline Biological & 21 & 56 & 33 \\
Cultural & 31 & 14 & 25 \\
None & 48 & 32 & 45 \\
\hline
\end{tabular}
H 9: $\mathrm{B}_{1}<\mathrm{B}_{2}<\mathrm{B}_{3}$
Ho 9: $\mathrm{B}_{1}=\mathrm{B}_{2}=\mathrm{B}_{3}$
$\mathrm{Chi}^{2}=28.21$
d. f. $=2, p>.05$ Ho rejected.

The second graders in this sample have the largest effect on the 
findings. Of the three grades, the second graders were more likely to show a biological concept of reproduction. This finding is significant, but since it does not fit either the hypothesis or the null hypothesis an alternative hypothesis is proposed:

$$
\mathrm{H}: \mathrm{B}_{1}<\mathrm{B}_{2}>\mathrm{B}_{3}
$$

To determine some of the factors that contributed to the judgments, the grade and sex of the artist of each picture were estimated. These estimates tested accuracy of judgment and provided the group with a method of isolating the factors that were most utilized in making judgments. Due to lack of time, all of these data will not be reported here. Of the 300 pictures, 168 were judged male, 132 female, 81 were judged as first graders, 121 second graders, and 98 third graders.

The ability of the judges to use these factors to determine the grade and sex of the sample is shown by the percentages of correct predictions. The percentages are given for correct estimations of grade, sex, and grade and sex. The estimates of sex are adjusted so that pictures with names on them are eliminated. First graders were estimated correctly $40 \%$, second graders $51 \%$, and third graders $53 \%$. Males were estimated correctly $69.1 \%$ and females $63 \%$. With grade and sex combined, the percentages are first male, $34 \%$, first female $26 \%$, second male $46 \%$, second female $36 \%$, third male $34 \%$, and third female $58 \%$. Males and the higher grades were 
more easily differentiated than the lower grades and females. The data indicate the factors in judging male pictures were more clearly obserwable than those used to judge female pictures. The third grade females were identified more frequently than any other grade and sex. This might indicate there are factors that more clearly differentiate their group of pictures from the other groups.

When the data are divided into categories by the estimated grade and sex, certain categories appear to have more influence on judgments than others. For instance, in the grouping of male objects, excluding trees, of the fifty-seven male objects pictured, fifty-two were judged to have been drawn by males. This was the most extreme of the examples, but otherwise the general impression is that the pictures were judged more by the content than by the Eriksonian concepts. The presence of elaboration in a picture gave it a better chance of being estimated as a female picture. Those pictures that were judged to have a bold use of color tended to be estimated as male and those pictures where color was used delicately tended to be grouped as female. Factors of tonality, space, and orientation were distributed about equally among the sexes.

The above are observations from the data and have not been subjected to statistical evaluation. These factors seem to have influenced judgments to a greater extent than others. It is most likely that the final estimates were dependent upon a combination of 
factors on the schedule as well as some that were not listed. These data suggest many other areas for investigation which will be discussed later in this chapter.

\section{CONCLUSIONS}

It was the purpose of this study to explore relationships between characteristics of children's art, and sex and grade level. It was hoped to find trends which would point to further research. This study tended to confirm the following conclusions.

I. Differences can be observed in children's art which can be related to the sex of the artist. Of statistical significance is the use of Objects by males, Elaboration by females, Bold use of color by males and Delicate use of color by females.

II. Differences can be observed in children's art which can be related to the grade level of the artist. The findings indicate that second graders tend to draw biological concepts of reproduction while first and third graders avoid drawing any reproduction concept. Second graders tend not to use a baseline. First graders draw more people. Second graders use less elaboration and fewer colors than first and third graders. Third graders tend more to fill in the background.

III. Differences in children's art related to sex and grade level can be observed, with low levels of agreement, by social workers. 
It is notable, however, that the group's observations of the quantifiable content such as Objects and number of colors were more reliable than the observations of more complex concepts such as Space, Orientation, and Tonality.

\section{INTERPRETATION OF FINDINGS}

The interpretation of the findings is affected by three factors. First, there are a number of uncontrolled variables. Second, there is a lack of research of children's art which would produce norms against which to measure findings. Third, the reliability of judgment was low.

The pictures used in the study were not collected by the group and therefore many variables could not be controlled. Data about the artist were not collected. Although information regarding sex and grade level was present, variables relating to age, maturity, social class, cultural background, art education, knowledge of reproduction, peer influence on the artist, and specific art materials available could not be controlled. Thus the influence of these uncontrolled variables cannot be determined if one wishes to generalize to larger populations. At least one variant cultural group existed in the collection, but the group could not be identified and its impact could not be measured.

The lack of norms against which to measure children's art 
made it difficult to draw standardized conclusions. There is some indication in the literature that children's performance varies with the task. It has been noted that free drawing produces different results than drawing in response to a topic, thus the factor of freedom becomes important. The amount of freedom given the children who produced the pictures for this study was not closely controlled. If classroom teachers followed the E. C. Brown Trust Foundation instructions, the children drew in response to at least one of the four particular statements listed in Chapter I. Freedom to interpret or to stray from the assignment may have varied dependent upon the particular classroom situation. A consideration which warrants study is the impact on art of an emotionally loaded topic such as reproduction. The effect of the child's attitudes toward sexual matters may influence his art in ways that a more neutral subject would not. It would be possible to examine this idea by comparing samples of the E. C. Brown Trust Foundation collection with another collection of pictures on non-sexual topics.

The research design of this study was strengthened by use of a large sample. From the collection of over 1, 000 pictures, 300 were observed. The large amount of data collected enabled the group to look at many combinations of factors that might have been ignored in a less comprehensive study.

Care was taken through training and the use of pretests to 
enhance accuracy of the observations. Nevertheless, concordance was low, demonstrating a complexity in art and a subjective element that is difficult, if not impossible, to overcome for scientific purposes.

Perhaps the most valuable contribution of the study was to point up the necessity of reporting reliability measures when dealing with art and its use as a projective technique for diagnosis.

Similarly, the study suggests that much attributed to art or to a child and his social characteristics must come from preknowledge about the child rather than from the art itself.

Judging the pictures blind was the most significant methodological contribution of the study.

\section{IMPLICATIONS FOR SOCIAL WORK}

The findings of this study illustrate some of the difficulties encountered when social work attempts to operationize and define concepts from many disciplines. The incorporation of knowledge and findings from various fields into the theoretical and practical bases of social work is a common practice. Attempts to measure and test the concepts which have been incorporated have not been common, and it is this lack of research which motivated this study. The implications of the study relate primarily to three areas: the use of art in social work, the problem of the reliability of social workers' 
observations about art, and the problem of translation of concepts from one discipline to another.

The findings indicate that it is possible for social work research to use material gathered for other purposes in meaningful ways. While this study indicates that there are some significant differences related to sex and to grade level, it is important to note that the findings reported are true for the group, not for each individual artist. This implies that social workers should be cautious about making judgments concerning a child based on categorical information.

The use of children's art as a social work tool for evaluating human behavior cannot be recommended until parameters and variations are established by research. However, art can have real value to social workers if they consider the child's use of art as an integral part of his life, rather than limiting its use to diagnosis. The importance of art as an experience in the development of the whole child seems worthy of further research by social work. The pictures viewed by the group seemed to have more meaning as a total collection than when examined individually. The field of art education deals with the creative experience of the child's life, but this is limited to his art. Social work might take advantage of its skill in understanding the relationship between the individual and his world to explore the implication of art in the total emotional, 
intellectual, and social development of the child.

In this study the group has investigated an area somewhat foreign to the usual jurisdiction of social work. While it has been found that knowledge pertinent to the field can be obtained, it is uncertain at this point how it can best be used. One thing is clear, children's art ought not be used as a primary basis for making significant diagnositic decisions which are unsupported by considerably wider understanding of the child's life. It is the hope of the group that the information obtained from this study can serve as a basis for further exploration of the development of the child as he projects his life experiences through art. 


\section{BIBLIOGRAPHY CITED}

1. Erikson, Erik H., Childhood and Society, second edition, New York: W. W. Norton, 1963.

2. Gaitskell, Charles D., Children and Their Art, Methods for the Elementary School, Willard B. Spalding, ed., New York: Harcourt, Brace and Company, 1958.

3. Kellogg, Rhoda, and Scott O'Dell, The Psychology of Children's Art, San Diego, California: GRM-Random House, 1967.

4. Kellogg, Rhoda, What Children Scribble and Why, Palo Alto, California: N-P Publications, 1959.

5. Hausman, Jerome J., "Children's Art Work and Their Sociometric Status," Research in Art Education, Fifth Yearbook, Kurtztown, Pennsylvania: 1954. pp. 131-151.

6. Burns, Robert, "Some Correlations of Design with Personality," Research in Art Education, Ninth Yearbook, Washington, D. C.: National Art Education Association, 1959. pp. $125-130$.

7. Freyberger, Ruth M., "Differences in the Creative Drawings of Children of Varying Ethnic and Socio-Economic Backgrounds in Pennsylvania Based on Samplings of Grades One Through Six," Research in Art Education, Seventh Yearbook, Kurtztown, Pennsylvania: National Art Education Association, 1956. pp. 115-125.

8. Lowenfeld, Viktor, Creative and Mental Growth, revised edition, New York: The Macmillan Company, 1952.

9. Lark-Horovitz, Betty, et al., Understanding Children's Art for Better Teaching, Columbus, Ohio: Charles Merrill Books, Inc., 1967. 
10. Corcoran, Ambrose, "Children's Responses to Color Stimuli," Research in Art Education, Seventh Yearbook, Kurtztown, Pennsylvania: National Art Education Association, 1956, pp. 84-95.

11. Dodd, Stuart C., The Probable Acts of Men, Vol. II, Iowa City, Iowa: State University of Iowa, 1963. 


\section{RECOMMENDED BIBLIOGRAPHY}

Associates of the E. C. Brown Trust Foundation, "Children's Art and Human Beginnings, " The Family Life Coordinator, XVI (July-October, 1967) reprinted by the E. C. Brown Trust Foundation, i-viii.

Block, Kathy, Children's Concepts of Being Born as Expressed in Their Drawings at School, E. C. Brown Trust Foundation: 1967. Unpublished manuscript.

Brittain, W. Lambert, Creativity and Art Education, Washington, D. C. : The National Art Education Association, n. d.

Clements, Robert D., Pete J. Carr, and Gerry B. Mendelson, "Subject or Process Motivation in the Elementary Grades," Art Education, XXI, pp. 21-26.

Cole, Natalie R., Children's Arts From Deep Down Inside, New York: The John Day Company, 1966.

Dunnett, Ruth, Art and Child Personality, London: Methuen and Co., Ltd., 1948.

Grozinger, Wolfgang, Scribbling, Drawing, Painting, Trans. E. Kaiser and E. Wilkins, New York: Frederick A. Praeger, Inc., 1955.

Lindstrom, Miriam, Children's Art, a Study of Normal Development in Children's Modes of Visualization, Berkeley, California: University of California Press, 1957.

Mendelowitz, Daniel M., "Children's Artistic Abilities Develop," In: Art for Children's Growing, Washington, D. C.: Association for Childhood Education International, 1955.

Rabin, Albert I., and Mary R. Haworth, editors, Projective Techniques with Children, New York: Grune and Stratton, 1960.

Viola, Wilhelm, Child Art, second edition, Peoria, Illinois: Charles A. Bennett Co., Inc., 1944. 
APPENDICES 
APPENDIX A

REPRESENTATIVE PICTURES 
APPENDIX B

THE SCHEDU LE 
No. Grade Sex Examiner Trial

\section{ORIENTATION}

1 . vertical

2. circular

3. other

\section{SPACE}

4. open

5. closed

6. indeterminate

\section{DIMENSIONS}

7. baseline shown

8. implied

9. absent

\section{PEOPLE}

10. total number

11. foetus

12 . baby

13. $\mathrm{x}$-ray preg.

14. preg. non $x$-ray

\section{AGE AND GENDER} Males

15. adult

16. child

17. indeterminate
AGE AND GENDER (Continued)

\section{Females}

18. adult

19. child

20. indeterminate

21. other

\section{REPRODUCTION}

22. biological

23. folk

24. cultural

25. religious

26. none

\section{ANIMALS}

27. birds

28. pets

29. other

\section{STRUCTURES}

30. $\mathrm{H}$ $B$ interior

31 . $\mathrm{H}$ B exterior

32. $\mathrm{H}$ B x-ray

33. indeterminate 
OBJECTS

34.

35. trees

36. smoke, paths, streets

37.

38.

39.

40.

41 .

42 . furniture cars, planes, machines doors open doors closed eggs and/or sperm suns, mandalas clouds

ELABORATION

43. marked detail of people

44. marked detail of picture

45. ornamentation

46. marked care of execution

47. marked symmetry

TONALITY 48. light colors

49. dark colors

50 . indeterminate

\section{INTENSITY OF COLOR}

51 . delicate

52. bold

53. indeterminate
COLOR

54. red

55. orange

56. yellow

57. blue

58. green

59. purple

60. brown

61. black

62. white

63. pink

64. other

65. total colors used

66. est. sex

67. est. grade

68. background filled in

69. background not filled in 